\title{
PREPULSE INHIBITION AND LATENT INHIBITION: THE ROLE OF DOPAMINE IN THE MEDIAL PREFRONTAL CORTEX
}

\author{
B. A. ELLENBROEK, * S. BUDDE and A. R. COOLS
}

Department of Psychoneuropharmacology, P.O. Box 9101, 6500 HB, Nijmegen, The Netherlands

\begin{abstract}
The prefrontal cortex has often been implicated in the pathophysiology of schizophrenia. Schizophrenic patients are known to suffer from certain information processing deficits, which can be detected, among others, in the prepulse inhibition and the latent inhibition paradigm. The present study was designed to investigate the role of dopamine receptors in the medial prefrontal cortex in prepulse inhibition and latent inhibition. The results show that the local application of the selective antagonist of the dopamine $\mathrm{D}_{1}$-like receptor family, $\mathrm{SCH} 39166$, into the medial prefrontal cortex dose-dependently reduced prepulse inhibition. Likewise, the selective antagonist of the dopamine $D_{2}$-like receptor family, sulpiride, injected into the medial prefrontal cortex dose-dependently reduced prepulse inhibition. Neither of these antagonists, however, influenced latent inhibition as measured with the conditioned taste aversion paradigm. These data further indicate that the neuronal substrates of latent inhibition and prepulse inhibition are clearly different.

Since the prefrontal cortex is intimately related to subcortical dopamine, the possible differential involvement of subcortical dopaminergic terminal fields in prepulse inhibition and latent inhibition is discussed. Copyright (C) 1996 IBRO. Published by Elsevier Science Ltd.
\end{abstract}

Key words: prepulse inhibition, latent inhibition, $\mathrm{D}_{1}$ receptors, $\mathrm{D}_{2}$ receptors, prefrontal cortex, animal model.

Schizophrenia has been referred to as the graveyard of neuropathology, ${ }^{29}$ indicating that it has been extremely difficult to detect clear and consistent pathological changes in the brains of schizophrenic patients. In spite of the fact that several authors have reported an overall decrease in brain volume, ${ }^{7,8.27}$ no localized lesion has so far been unequivocally identified. It seems, therefore, that schizophrenia is accompanied by more subtle and diffuse brain abnormalities. Recent studies using computer tomography and magnetic resonance imaging techniques have further substantiated this claim. Rather than gross abnormalities, small reductions in the volume of the frontal and the temporal cortex have been reported. ${ }^{4,30}$ These changes in frontal cortex morphology have been linked to the more severe cases of schizophrenia, ${ }^{1,31}$ and are considered to be causal factors in the disease, rather than secondary to it. ${ }^{38}$

One problem in studying the involvement of brain structures in schizophrenia has been the lack of adequate animal models for this disease. However, the notion that schizophrenic patients have disturbances in information processing (which can be measured in humans and rats with virtually identical

*To whom correspondence should be addressed.

Abbreviations: ANOVA, analysis of variance; 6-OHDA, 6-hydroxydopamine; SCH 23390, 7-chloro-9-hydroxy3-methyl-1-phenyl-2,3,4,5-tetrahydro-1 H-3-benzazepine; SCH 39166, 4-(4-chloro-3-methoxyphenyl)-1,2-dihydronaphthalene. methods) has brought an important change in the line of animal modelling. Thus, paradigms like the prepulse inhibition of the acoustic startle response, $P_{50}$ event-related potential gating and latent inhibition have been considered to represent valid animal models for cognitive disturbances occurring in schizophrenia. ${ }^{14,18}$

So far, the role of the prefrontal cortex in these information processing paradigms has not been extensively investigated. Swerdlow et al. ${ }^{33}$ reported that 6-hydroxydopamine (6-OHDA) lesions of the frontal cortex have little effect on prepulse inhibition. Moreover, stimulating supersensitive dopamine receptors (resulting from such frontal cortical 6-OHDA lesions) with low doses of apomorphine did not affect prepulse inhibition. In agreement with this, local injections of dopamine within the orbital part of the frontal cortex do not affect prepulse inhibition. ${ }^{34}$ However, more recent studies have shown that very extensive 6-OHDA lesions in the prefrontal cortex (leading to a $90 \%$ reduction in tissue dopamine levels) result in diminished prepulse inhibition. ${ }^{9}$ Unfortunately, 6-OHDA not only lesions dopaminergic, but also noradrenergic and serotonergic fibres. In fact, even after pretreatment with desipramine, the doses of 6-OHDA used led to significant reductions in the levels of noradrenaline and serotonin in the medial prefrontal cortex. ${ }^{22}$ Given the fact that there are close interactions between noradrenergic and dopaminergic terminals in the prefrontal cortex, ${ }^{35}$ such non- 
specific 6-OHDA lesions might lead to erroneous conclusions with respect to the role of dopaminc. Moreover. these lesioning experiments do not adLress the question of which subtype of dopamine receptors is involved in prepulse inhibition.

In the present study we have therefore decided to reduce the dopaminergic neurotransmission more selectively, by local injections of the dopamine antagonists 4-(4-chloro-3-methoxyphenyl)-1,2-dihydronaphthalene ( $\mathrm{SCH}$ 39166; selective for the dopamine $D_{1}$-like receptor family) and DL-sulpiride (selective for the dopamine $D_{2}$-like receptor family). These drugs are known to be highly selective for $D_{1}$ and $D_{2}$ receptors, respectively. ${ }^{12.25}$ In addition to studying the effects of these manipulations on prepulse inhibition, we studied the effects on latent inhibition using the conditioned taste aversion paradigm, since the role of the prefrontal cortex in this paradigm has, to our knowledge, not yet been investigated.

\section{EXPERIMENTAL PROCEDURES}

\section{Animals and surgery,}

Male Wistar rats (bred at the Central Animal Laboratory of the University of Nijmegen), weighing 180-200 g at the time of the operation, were used. Rats were stereotaxically implanted with guide cannulae aimed at the prelimbic part of the prefrontal cortex, under sodium pentobarbital anaesthesia (Narcoved", $60 \mathrm{mg} / \mathrm{kg}$ i.p.). In a recent c-Fos study (Ellenbroek et al., unpublished observations), we have found that especially this part of the prefrontal cortex is involved in prepulse inhibition. Guide cannulae (outer diameter, $0.65 \mathrm{~mm}$; inner diameter, $0.3 \mathrm{~mm}$ ) were bilaterally implanted at the following coordinates: A 10.5, V 2.5, L $-0.8 \mathrm{~mm}$. The cannulae were implanted under a lateral angle of $20^{\circ}$. Cannulae were fixed to the skull using dental cement (Durelon ESPS; carboxylate cement), aided by the attachment of two screws. After the operation, the rats were returned to the animal room, where they were allowed to recover for at least 10 days before experiments were started. Rats were kept on a 12-h day/night cycle, with lights on at 07.00. Food and water were available all libitum. Only experimentally and drug-naive rats were used throughout the study.

\section{Prepulse inhibition paradigm}

The prepulse inhibition paradigm was performed using standard starlle equipment (San Diego Instruments). The cage consisted of a Plexiglas tube $(8.2 \mathrm{~cm}$ diameter, $25 \mathrm{~cm}$ length) resting on a plastic frame. A piezoelectric accelerometer mounted under the tube detected and transduced the motion of the tube. Stimulus delivery was done using the SR-LAB software, via a speaker mounted $10 \mathrm{~cm}$ above the cylinder. The computer software also digitized, rectified and recorded the response of the accelerometer, with 100 readings of $1 \mathrm{~ms}$ collected from the beginning of stimulus onset. Startle amplitude was defined as the average of the 100 readings. The whole system was mounted within a sound attenuating chamber. Throughout the startle session a background level of $70 \mathrm{~dB}$ was maintained.

Rats were bilaterally injected using a Hamilton syringe $(0.5 \mu \mathrm{l}$ per side over a 10 -s period) immediately before the start of the experimental session. SCH 39166 (kindly donated by Schering, U.S.A.) was dissolved in water $(250 \mathrm{ng} /$ $0.5 \mu l, n=9$ animals; $500 \mathrm{ng} / 0.5 \mu \mathrm{l}, n=9$ animals); DL. sulpiride (Sigma, U.S.A.) was diluted in a minute volume of acetic acid, diluted with water to the final concentration
$(12.5 \mathrm{ng} / 0.5 \mu \mathrm{l}, \quad n=7 ; \quad 25 \mathrm{ng} / 0.5 \mu \mathrm{l}, \quad n=9 ; \quad 50 \mathrm{ng} / 0.5 \mu \mathrm{l}$, $n=10 ; 100 \mathrm{ng} / 0.5 \mu \mathrm{l}, n=10$ ), after which the $\mathrm{pH}$ was adjusted to a value of 7.0 with sodium bicarbonate. As a control, distilled water was injected $(0.5 \mu 1, n=10)$. The syringe was held in place for an additional $10 \mathrm{~s}$ to minimize diffusion along the needle tract. The startle session started with a 5 -min habituation session in the startle system. After this habituation period five startle pulses $[40-\mathrm{ms}$ broad band burst of $120 \mathrm{~dB}(\mathrm{~A})$; the $A$ refers to the $A$ weighting scale for sound measurement] were delivered to test basal startle responsiveness. Next, five blocks of seven trials were delivered to mcasure prepulse inhibition. Each of these blocks consister of two startle trials, one no-stimulus condition and one of four different prepulse-startle pairings (prepulse trials), which were administered pseudo-randomly to ensure that each prepulse trial occurred only once in each block and that the two startle-alone trials did not occur in two consecutive trials. In these prepulse trials, the prepulse was either $2,4,8$ or $16 \mathrm{~dB}(\mathrm{~A})$ above background. These prepulses were always 20 -ms broad band bursts and were always followed by a startle pulse $[120 \mathrm{~dB}(\mathrm{~A})] 100 \mathrm{~ms}$ later. The session was terminated by five additional startle trials to allow a measure for startle habituation. The interval between two trials was between 10 and $20 \mathrm{~s}$.

The degree of prepulse inhibition (\%) was calculated according to the formula:

$$
100-\frac{\text { Startle amplitude on prepulse trial }}{\text { Startle amplitude on startle trial }} \times 100
$$

\section{Latent inhibition paradigm}

Latent inhibition was measured using the conditioned taste aversion paradigm. Rats were housed individually with food freely available throughout the experiment. Water bottles were removed from the cages $24 \mathrm{~h}$ before the start of the experiment. On the first day of the experiment rats were subdivided into two groups: a pre-exposed group and a non-prc-exposed group. The whole experiment was performed in the home cage of the rats. The pre-exposed group received a botlle with $50 \mathrm{ml}$ of a $5 \%$ sucrose solution, whereas the non-pre-exposed group received a bottle with $50 \mathrm{ml}$ of plain tap water for $30 \mathrm{~min}$. After these $30 \mathrm{~min}$, the bottles were weighed to determine the amount of solution drunk. This procedure wals repeated on days 2 and 3 . On day 4 , all rats were given a bottle of $50 \mathrm{ml}$ of a $5 \%$ sucrose solution, again for $30 \mathrm{~min}$. Immediately after the $30 \mathrm{~min}$, each rat was treated with $75 \mathrm{mg} / \mathrm{kg}$ of lithium chloride $(7.5 \mathrm{ml} / \mathrm{kg}$, i.p.). On the final test day (day 5), the rats received one bottle with $50 \mathrm{ml}$ of tap water and one bottle with $50 \mathrm{ml}$ of $5 \%$ sucrose. The degree of conditioned taste aversion (\%) was calculated using the formula:

\section{Sucrose consumed $(\mathrm{g})$}

Sucrose consumed $(\mathrm{g})+$ Tap water consumed $(\mathrm{g})$

The selective antagonist of the dopamine $D_{1}$-like receptor family SCH 39166 (kindly donated by Schering, Bloomfield, U.S.A.; $500 \mathrm{ng} / 0.5 \mu \mathrm{l}$, nine animals for pre-exposed and nine for non-pre-exposed group), the selective antagonist of the dopamine $\mathrm{D}_{2}$-like receptor family $\mathrm{DL}$-sulpiride (Sigma; $12.5 \mathrm{ng} / 0.5 \mu \mathrm{l}, n=7 ; 25 \mathrm{ng} / 0.5 \mu \mathrm{l}, n=10 ; 100 \mathrm{ng} / 0.5 \mu \mathrm{l}, n=9$ animals for pre-exposed and non-pre-exposed groups) or water $(0.5 \mu \mathrm{l}, n=10$ for pre-cxposed and non-pre-exposed group) was administered in freely moving rats using a Hamilton syringe $(0.5 \mu \mathrm{l}$ per side over a 10 -s period) immediately before days $1-4$. No injection was given on the final test day (day 5). The needle was held in place for an additional $10 \mathrm{~s}$ to minimize diffusion along the needle tract.

\section{Data analysis and histological verification}

In the prepulse inhibition experiment, a mixed analysis of variance (ANOVA) was used, with the different prepulse 

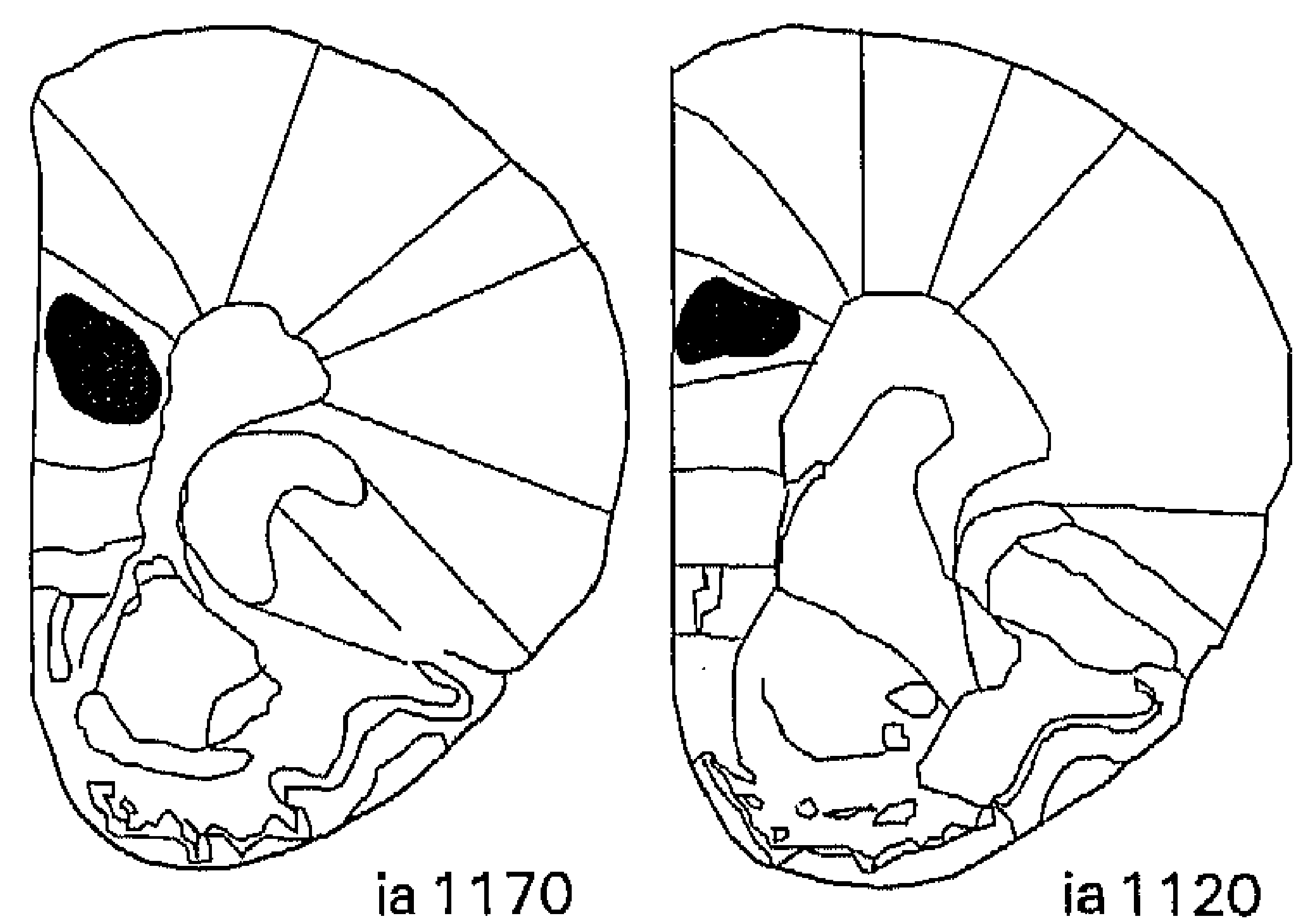

ia 1170

ia 1120

Fig. 1. The area (hatched) in which the injections into the medial prefrontal cortex were localized (after Paxinos and Watson $\left.{ }^{28}\right)$.

intensities as within-subject factors and the drug treatments as between-subject factors. In case of statistical differences, a one-way ANOVA was used to analyse the difference between the individual doses for each prepulse intensity. A $P$ value of less than $5 \%$ was considered to indicate a significant difference. In the latent inhibition paradigm, the effects of DL-sulpiride and SCH 39166 on liquid consumption were analysed separately for both the pre-exposed and the non-pre-exposed groups using a one-way ANOVA. The occurrence of latent inhibition was analysed by one-way ANOVA comparison between the pre-exposed and the non-pre-exposed groups.

After the experiments rats were killed with an overclose of sodium pentobarbital and perlused (transcardially) with a $3 \%$ formaldehyde solution. Brains were removed and stored in formaldehyde for at least three days, after which they were transferred to a $10 \%$ sucrose solution for an additional day. Frozen sections of $30 \mu \mathrm{m}$ were collected on glass slides coated with glycerinc and stained with Cresyl Violet to verify the injection sites.

\section{RESULTS}

\section{Injection sites}

Almost all of the rats had injections situated within the boundaries of the cingulate cortex area 3 as delineated by Paxinos and Watson. ${ }^{28}$ The area in which the injections were localized is shown in Fig. 1. The data of rats with injection sites outside this area $(n=2)$ were discarded from the analysis.

\section{Prepulse inhibition}

The local application of DL-sulpiride or SCH 39166 into the medial prefrontal cortex did not affect basal startle reactivity (Fig. 2A) nor habituation (measured as the ratio of the last five over the first five startle trials; data not shown).

The effects of local application of SCH 39166 on prepulse inhibition are shown in Fig. 2B. The mixed ANOVA showed a significant diug effect $\left(F_{\mathrm{l}, 26}=\right.$ $7.78, P<0.01$ ) and a significant effect of prepulse intensity $\left(F_{4,22}=18.7, P<0.001\right)$, but no drug $\times$ prepulse intensity interaction $\left(F_{3,23}=1.12, P 0.2\right)$. Both doses of SCH $39166(250$ and $500 \mathrm{ng} / 0.5 \mu \mathrm{l})$ significantly reduced prepulse inhibition at the low-intensity prepulses $[2$ and $4 \mathrm{~dB}(\mathrm{~A})]$, whereas the highest dose $(500 \mathrm{ng} / 0.5 \mu \mathrm{l})$ significantly reduced prepulse inhibition at all prepulse intensities (ANOVA with post hoc Duncan, $P<0.05$ ).

The effects of local application of DL-sulpiride on prepulse inhibition are shown in Fig. 2C. Note that the same control group (intracerebral injection of water) was used for both the experiments with $\mathrm{SCH}$ 39166 and DL-sulpiride. The mixed ANOVA showed a significant effect of drug $\left(F_{1,43}=9.62, P<0.01\right)$ and of prepulse intensity $\left(F_{4,39}=17.4, P<0.001\right)$, but no drug $\times$ prepulse intensity interaction, although there was a tendency $\left(F_{3,40}=2.61, P=0.07\right)$. Oneway ANOVA followed by post hoc Duncan showed that $12.5 \mathrm{ng} / 0.5 \mu \mathrm{l}$ did not significantly affect prepulse inhibition. Post hoc Duncan further showed that a dose of $25 \mathrm{ng} / 0.5 \mu \mathrm{l}$ sulpiride significantly reduced prepulse inhibition at low-intensity prepulses $[2$ and $4 \mathrm{~dB}(\mathrm{~A})$ ], whereas the two highest doses (50 and $100 \mathrm{ng} / 0.5 \mu \mathrm{l})$ significantly reduced prepulse inhibition at all prepulse intensities tested (see Fig. 2C).

\section{Latent inhibition}

SCH 39166 did not affect liquid consumption during the first three days of pre-exposure for either the pre-exposed or the non-pre-exposed group (Fig. $3 \mathrm{~A})$. Likewise, no significant effects were seen on fluid intake on day 4 (conditioning day) or on the final test day (data not shown).

Figure 3B clearly shows that SCH 39166 (500 ng/ $0.5 \mu$ l) did not affect the latent inhibition. This observation was confirmed by statistical evaluation of the percentage of sucrose consumed on the final test day: a significant effect of pre-exposure was seen in both the control group $\left(F_{1,18}=6.51, P<0.02\right)$ and the SCH 39166 group $\left(F_{1,16}=20.59, P<0.0003\right)$.

DL-Sulpiride $(12.5-100 \mathrm{ng} / 0.5 \mu \mathrm{l})$ did not affect liquid consumption during the first three days of pre-exposure for either the pre-exposed or the nonpre-exposed group, with one exception. On day 3 , the pre-exposed group showed a significant drug effect $\left(F_{3,32}=9.17, P<0.0002\right)$, which was entirely due to a significantly increased amount of sucrose drunk by the group treated with $12.5 \mathrm{ng}$ DL-sulpiride (see Fig. $3 \mathrm{~A})$. Note that the same control group (intracerebral injection of water) was used for both experiments with SCH 39166 and DL-sulpiride. More importantly, there were no differences in sucrose consumption on day 4 (the conditioning day) nor in sucrose or water consumption on the test day (data not shown). This lack of a drug effect was also seen in percentage sucrose consumed on the final test day.

Figure $3 \mathrm{C}$ shows that latent inhibition occurred in all experimental groups. This was confirmed by statistical evaluation comparing the percentage sucrose consumed between pre-exposed and non-pre-exposed groups: there was a significant effect of pre-exposure in the control group $\left(F_{1,18}=6.51, P<0.02\right)$ and in all 


\section{MEAN FLUID INTAKE DURING PREEXPOSURE} Effoote of $8 \mathrm{CH} 39166$ and sulpirid in to modial profron tal oortex

A

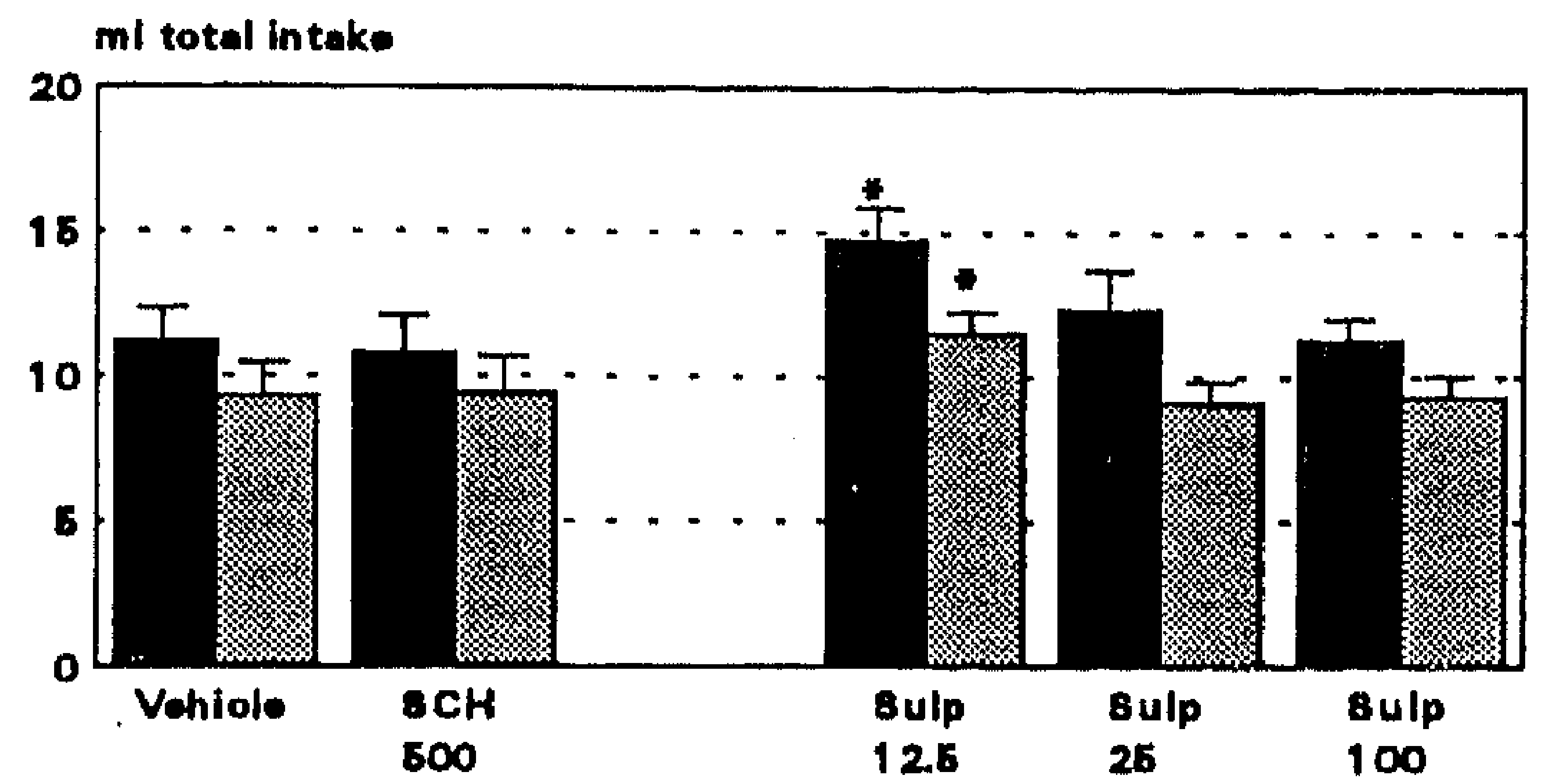

Mrooxpoued 政Non-prooxpoeod

LATENT INHIBITION

\section{Effect of SCH 39166 into Medial Prefrontal Cortex}

B

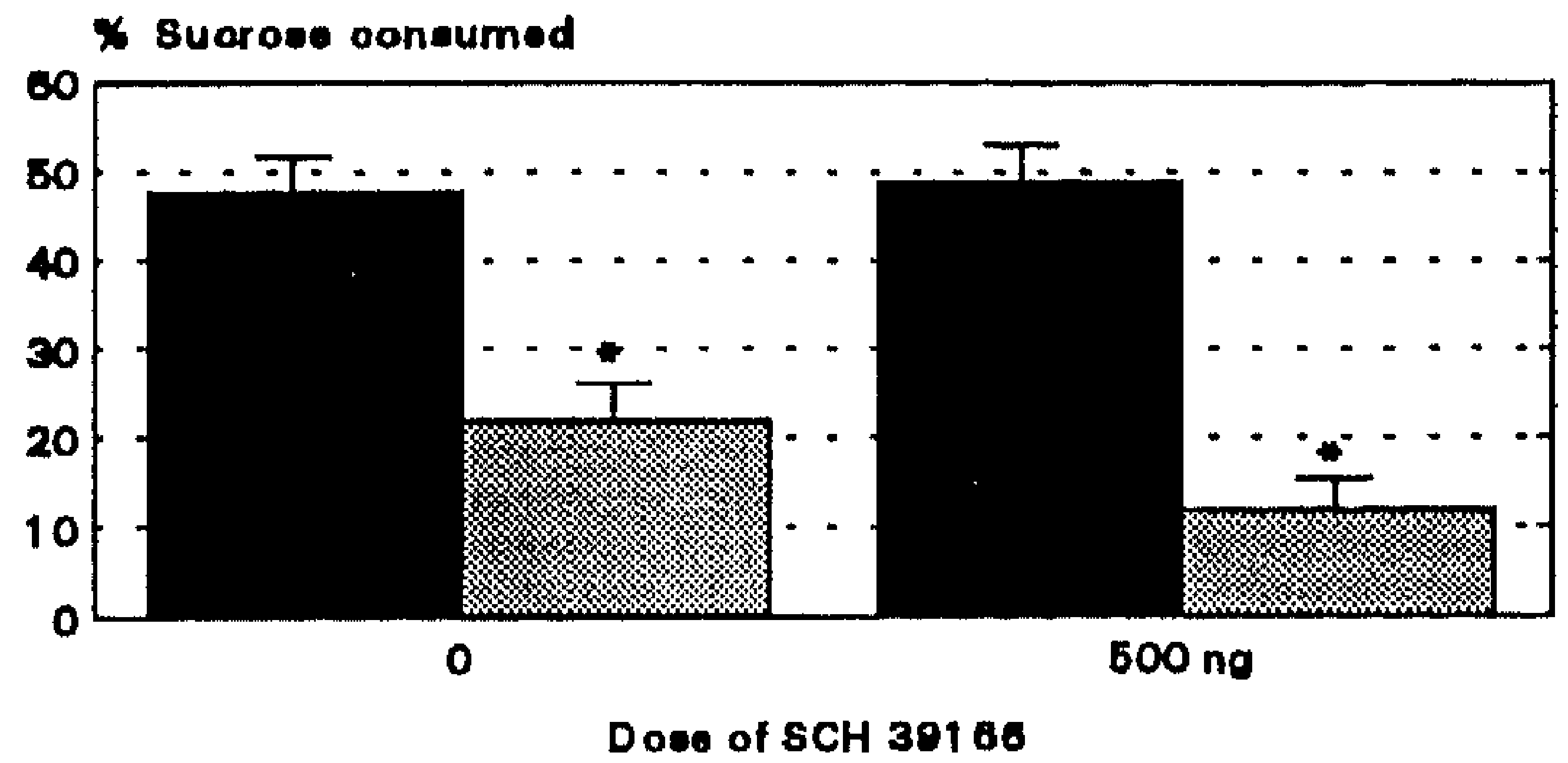

Proexposed Nonproexpoued

LATENT INHIBITION

Effect of Sulpiride into Medial Prefrontal Cortex

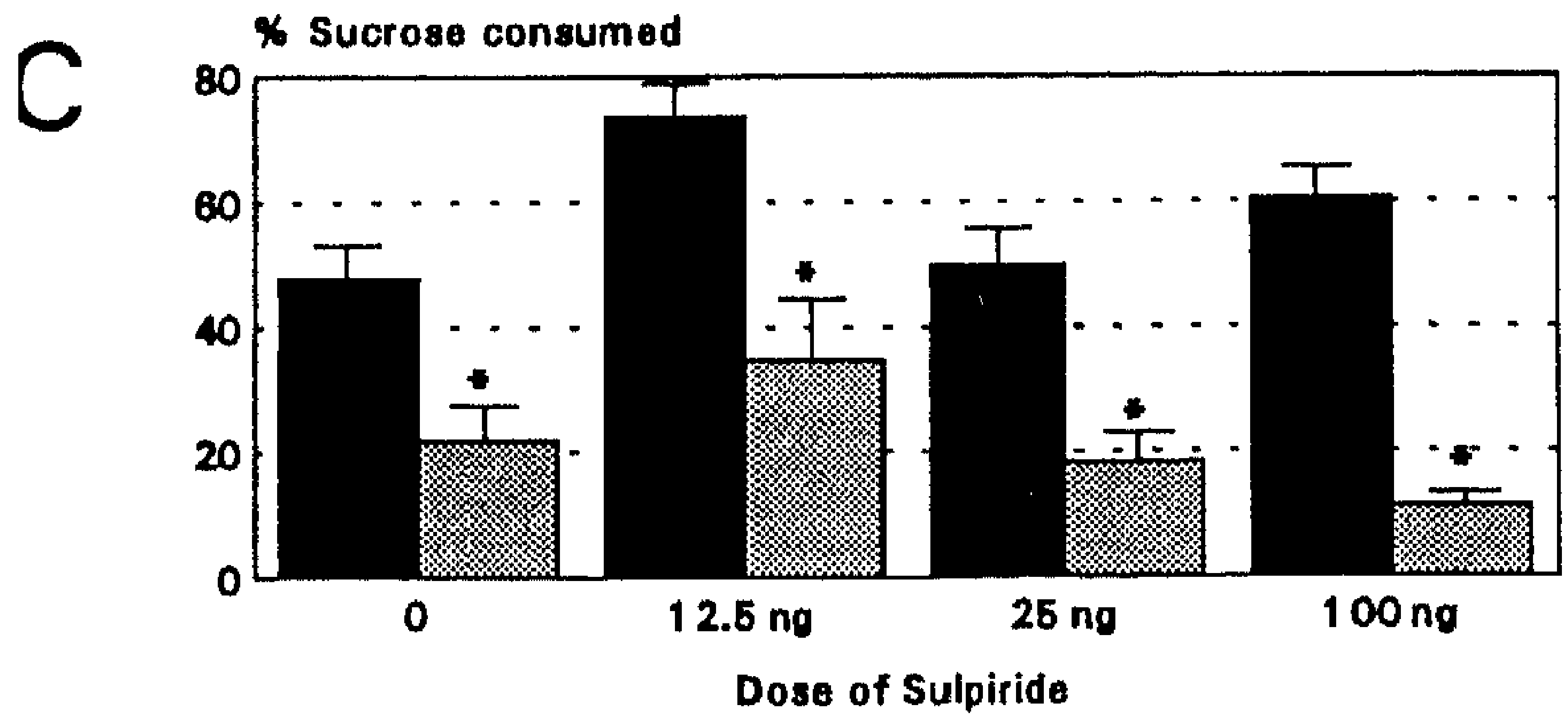

Proexposed Nonpreexposed

Fig. 3. (A) The effects of local application of SCH 39166 and DL-sulpiride on the mean liquid intake during the first three days of pre-exposure. *Significant differences vs control. (B, C) The effects of SCH 39166 (B) or DL-sulpiride (C) injected into the medial prefrontal cortex on the conditioned taste aversion paradigm. The percentage of sucrose drunk on the final test day is shown on the ordinate. The drugs are represented on the abscissa. Note that the same control group was used for both the SCH 39166 and the DL-sulpiride experiments. ${ }^{*} P<0.05$ vs pre-exposed group (ANOVA). 
DL-sulpiride-treated groups $\left(12.5 \mathrm{ng}, F_{1,10}=7.84\right.$, $P<0.02 ; \quad 25 \mathrm{ng}, \quad F_{1.20}=9.79, \quad P<0.005 ; 100 \mathrm{ng}$, $\left.F_{1,16}=44.57, P<0.0001\right)$.

\section{DISCUSSION}

The present results show that blockade of dopamine receptors within the medial prefrontal cortex (especially the prelimbic area or the cingulate cortex area 3 as described by Paxinos and Watson ${ }^{28}$ ) significantly reduced prepulse inhibition, whereas it had no effect on the degree of latent inhibition as measured with the conditioned taste aversion paradigm. Before discussing the relevance of these data, it is important to realize the possible effects of the stereotaxic operation or the intracerctral injection of vehicle (water). When the data presented in the present paper are compared to the literature in general, and our own previous data, it appears that neither the operation nor the injection of water had a large effect on prepulse inhibition. ${ }^{2,16}$ Much fewer data have been presented with respect to the latent inhibition/conditioned taste aversion paradigm. However, the data on the control injections are in line with previously reported data on normal nontreated rats. ${ }^{15}$ Moreover, in a recent publication we have shown that the local intracerebral injection of water into the nucleus accumbens or the neostriatum led to almost identical effects in the latent inhibition/ conditioned taste aversion paradigm as the systemic application of water. ${ }^{17}$ These data clearly suggest that intracerebral injections of water can be used as appropriate controls. This is not surprising, given the fact that this solution, although hypotonic, is injected in a minute quantity $(0.5 \mu \mathrm{l})$ in extracellular surroundings with a large buffering capacity. Although sulpiride was dissolved in a minute quantity of $1 \mathrm{~N}$ acetic acid we decided to use the same controls for both experiments, since the concentration of acetic acid in the final solution was extremely small (less than $0.01 \mathrm{M}$ ).

The data, with respect to prepulse inhibition, seem to be in agreement with an earlier study in which a decrease in prepulse inhibition was seen after large 6-OHDA lesions in the medial prefrontal cortex, ${ }^{9}$ although less extensive 6-OHDA lesions have previously been reported to be ineffective. ${ }^{33}$ This might indicate that the blockade of dopamine receptors obtained in the present study was almost complete. Unfortunately, it is impossible to calculate the degree of receptor blockade induced by a local injection of a drug, since this is, among others, dependent on the rate of diffusion into the synaptic cleft, which is virtually unknown. However, there are two important differences between the 6-OHDA studies and the present study. First of all, in the 6-OHDA study, rats were tested one or two weeks after lesioning. It is well known that compensatory mechanisms become active during this period. Secondly, as discussed in the Introduction, the 6-OHDA lesion also leads to reductions in serotonin and noradrenergic neurotransmission. $^{22}$ Since these neurotransmitters are known to be intimately related to the dopaminergic transmission, a complex interaction pattern may result from these general lesions. For instance, it has been shown that the noradrenaline reuptake inhibitor desipramine enhances extracellular levels of dopamine in the medial prefrontal cortex. ${ }^{10,20}$ This has been taken to indicate that in the medial prefrontal cortex dopamine is taken up by noradrenergic terminals, ${ }^{10}$ implying that an additional lesioning of noradrenergic fibres may lead to enhanced dopamine levels (due to a reduced reuptake of dopamine into these noradrenergic terminals).

There also appears to be a close and complex interaction between dopamine and serotonin within the prefrontal cortex. Thus, serotonin-3 agonists, as well as serotonin-2A antagonists, have been reported to increase dopamine release within the prefrontal cortex. ${ }^{11,31}$ These data indicate that the combined lesioning of dopaminergic, noradrenergic and serotonergic terminals may lead to complex changes in the dopaminergic transmission.

The present study shows that blockade of dopamine receptors leads to the same effects, irrespective of whether they belong to the dopamine $\mathrm{D}_{1}$-like family or the dopamine $\mathrm{D}_{2}$-like family. $\mathrm{SCH}$ 39166 and DL-sulpiride produced similar effects on prepulse inhibition and both lacked effect in the latent inhibition paradigm. At first sight, these data seem to be in disagreement with the effects of systemic application of dopamine antagonists. Both $\mathrm{D}_{1}$ and $D_{2}$ receptor antagonists have been shown to enhance prepulse inhibition when given systemically. $^{21,32}$ This suggests that the effects of systemically applied dopamine antagonists are not mediated via the prefrontal cortex, but possibly via subcortical mechanisms. There is ample evidence that blockade of dopamine within the medial prefrontal cortex leads to enhanced dopaminergic transmission in the nucleus accumbens. Thus, 6-OHDA lesions of the medial prefrontal cortex lead to an increase in footshock-induced or reward-induced dopamine levels in the nucleus accumbens. ${ }^{13,26}$ Likewise, local application of dopamine agonists within the medial prefrontal cortex reduce in vivo dopamine metabolism in the nucleus accumbens. ${ }^{23}$ In other words, there appears to be an opposite relationship between the dopaminergic transmission at the level of the medial prefrontal cortex and the nucleus accumbens. The behavioural data presented here appear to be in agreement with this, since there have been several reports of diminished prepulse inhibition after local application of dopaminergic agonists into the nucleus accumbens. ${ }^{34,37}$ There are, however, contrasting data with respect to the dopaminergic receptor in the medial prefrontal cortex that is involved in this interaction. In a recent study, the $D_{1}$ antagonist 7-chloro-9-hydroxy-3-methyl-1-phenyl-2,3,4,5-tetrahydro-1H-3-benzazepine (SCH 23390) was found to 
enhance amphetamine-induced locomotion, whereas the $\mathrm{D}_{2}$ antagonist DL-sulpiride was without effect. ${ }^{36}$ Likewise, Louilot et al..$^{23}$ found that application of SCH 23390 into the medial prefrontal cortex was more effective in enhancing the extracellular dihydroxyphenylacetic acid concentrations in the nucleus accumbens than application of DL-sulpiride (although the latter drug was not without effect). At present it is unclear how these data fit in with the present observation that both SCH 39166 and DLsulpiride reduced prepulse inhibition. One possible explanation might be that the effects of SCH 39166 are mediated via the nucleus accumbens, whereas the effects of DL-sulpiride are not. Experiments with cannulae aimed at the prefrontal cortex and the nucleus accumbens might provide a way of studying this hypothesis.

In contrast to the clear disruptive effects of $\mathrm{SCH}$ 39166 and DL-sulpiride on prepulse inhibition, neither drug was able to disrupt latent inhibition. If anything, there appeared to be a slight increase in latent inhibition. However, the design used in the present set of experiments (with three-day preexposure) led to an almost maximal degree of latent inhibition, making it difficult to detect further enhancement. Experiments using a shorter duration of pre-exposure time (one instead of three days) ${ }^{16}$ are currently underway to investigate this possibility. Although DL-sulpiride, at the lowest dose tested, showed a small, but significant, enhancement of the sucrose preference consumption in the pre-exposed group (Fig. 3B), this might be due to the larger amount of liquid consumed during pre-exposure (Fig. 3A), since it is well known that the degree of latent inhibition is positively correlated with the amount of pre-exposure. ${ }^{24}$ However, higher doses of DL-sulpiride, as well as a relatively high dose of SCH 39166 , were ineffective. To our knowledge, only one study has investigated the role of dopamine receptors in the prefrontal cortex on latent inhibition. ${ }^{6}$ This author found that the local application of high doses of cis-flupenthixol $(12 \mu \mathrm{g} / 0.5 \mu \mathrm{l})$ into the prelimbic cortex reduced latent inhibition in the conditioned suppression paradigm. However, close inspection of the analysis shows that the reduction of latent inhibition was due to an enhanced suppression ratio in the non-pre-exposed group rather than due to a decrease in the pre-exposed group. In fact, the suppression ratios of the pre-exposed control and the pre-exposed flupenthixol groups were virtually identical. In other words, flupenthixol seems to affect the learning of the conditioned suppression paradigm rather than the latent inhibition process. Extending the above-mentioned findings, suggesting that the effects of SCH 39166 (and possibly of DL-sulpiride) in the medial prefrontal cortex are mediated via the nucleus accumbens, leads to the hypothesis that the nucleus accumbens is not involved in the latent inhibition as measured with the conditioned taste aversion paradigm. This is in agreement with previous data from our laboratory, showing that local injections of amphetamine into the nucleus accumbens did not affect latent inhibition. In contrast, local injections of amphetamine into the dorsal striatum did affect latent inhibition. ${ }^{17}$

\section{CONCLUSIONS}

The present study shows that local application of SCH 39166 (a selective antagonist of the dopamine $\mathrm{D}_{1}$-like receptor family) and of DL-sulpiride (a selective antagonist of the dopamine $D_{2}$-like receptor family) into the medial prefrontal cortex reduced prepulse inhibition of the acoustic startle response. Neither treatment, however, affected latent inhibition of the conditioned taste aversion paradigm. These results add further support to the hypothesis that these aspects of information processing are mediated via different neuronal mechanisms. This appears to be in agreement with data on schizophrenic patients. Although both prepulse inhibition ${ }^{5}$ and latent inhibition ${ }^{19}$ appear to be disturbed in schizophrenic patients, latent inhibition, but not prepulse inhibition, appears to be normalized after treatment. ${ }^{3,4}$

\section{REFERENCES}

1. Andreasen N. C., Ehrhardt J. C., Swayze V. W. II, Alliger A. J., Yuh W. T. C., Cohen G. and Ziebell S. (1990) Magnetic resonance imaging of the brain in schizophrenia: the pathophysiologic significance of structural abnormalities. Archs gen. Psychiat. 47, 35-44.

2. Bakshi V. P. and Geyer M. A. (1995) Antagonism of phencyclidine-induced deficits in prepulse inhibition by the putative atypical antipsychotic olanzapine. Psychophamacology 122, 198-201.

3. Baruch I., Hemsley D. R. and Gray J. A. (1988) Differential performance of acute and chronic schizophrenics in a latent inhibition task. J, nerv. ment. Dis. 176, 598-606.

4. Bogerts B., Falkai P., Greve B., Schneider T. and Pfeiffer U. (1993) The neuropathology of schizophrenia: past and present. J. Hirnforsch. 34, 193-205.

5. Braff D. L., Grillon C. and Geyer M. A. (1992) Gating and habituation of the startle reflex in schizophrenic patients. Archs gen. Psychiat. 49, 206-215.

6. Broersen L. M., Heinsbroek R. P. W., De Bruin J. P. C. and Olivier B. (1996) Effects of local application of dopaminergic drugs into the medial prefrontal cortex. Biol. Psychiat. (in press).

7. Brown R., Colter M., Corsellis J. A. N., Crow T. J., Frith C. D., Johnstone E. C., Owens D. G. C. and Robert G. W. (1986) Postmortem cvidence of structural brain changes in schizophrenia. Archs gen. Psychiat. 43, 36-42.

8. Bruton C. J., Crow T. J., Frith C. D., Johnstone E. C., Owens D. G. and Roberts G. W. (1990) Schizophrenia and the brain: a prospective clinico-neuropathological study. Psychol. Med. 20, 285-304. 
9. Bubser M. and Koch M. (1994) Prepulse inhibition of the acoustic startle response of rats is reduced by 6-hydroxydopamine lesions of the medial prefrontal cortex. Psychopharmacology 113, 487-492.

10. Carboni E., Tanda G. L., Frau R. and DiChiara G. (1990) Blockade of the noradrenaline carrier increases extracellular dopamine concentrations in the prefrontal cortex: evidence that dopamine is taken up in vivo by noradrenergic terminals. J. Neurochem. 55, 1067-1070.

11. Chen J., Paredes W., Van Praag H. M., Lowinson J. H. and Gardner E. L. (1992) Presynaptic dopamine release is enhanced by 5-HT3 receptor activation in medial prefrontal cortex of freely moving rats. Synapse 10, $264-266$.

12. Christensen A. V. (1985) Classification of neuroleptics: implications for tardive dyskinesia. Pol. J. Phamac. Phamm. 37, 295-309.

13. Deutch A. Y., Clark W. A. and Roth R. H. (1990) Prefrontal cortical dopamine depletion enhances the responsiveness of mesolimbic dopamine neurons to stress. Brain Res. 521, 311-315.

14. Ellenbroek B. A. and Cools A. R. (1990) Animal models with construct validity for schizophrenia. Behav. Pharmac. $1,469-490$.

15. Ellenbroek B. A. and Cools A, R. (1995) Maternal separation reduces latent inhibition in the conditioned taste aversion paradigm. Neurosci. Res. Commun. 17, 27-33.

16. Ellenbroek B. A., Geyer M. A. and Cools A. R. (1995) The behavior of APO-SUS rats in animal models with construct validity for schizophrenia. J. Neurosci. 15, 7604-7611.

17. Ellenbroek B. A., Knobbout D. A. and Cools A. R. (1996) The role of mesolimbic and nigrostriatal dopamine in latent inhibition as measured with the conditioned taste aversion paradigm. Psychopharmacology (in press).

18. Geyer M. A. and Markou $\Lambda$. (1995) Animal models of psychiatric disorders. In Psychopharmacology: Fourth Generation of Progress (eds Bloom F.E. and Kupfer D.J.), pp. 787-798. Raven Press, New York.

19. Gray N. S., Pilowsky L. S., Gray J. A. and Kerwin R. W. (1995) Latent inhibition in drug naive schizophrenics: relationship to duration of illness and dopamine D2 binding using SPECT. Schizophr. Res. 17, 95-107.

20. Gresch P. J., Sved A. F., Zigmond M. J. and Finlay J. M. (1995) Local influence of endogenous norepinephrine on extracellular dopanine in rat medial prefrontal cortex. J. Netrochem. 65, 111-116.

21. Hoffman D. C. and Donovan $H$. (1994) $D_{1}$ and $D_{2}$ dopamine receptor antagonists reverse prepulse inhibition deficits in an animal model for schizophrenia. Psy'chopharmacology $115 \mathrm{~m}, 447-453$.

22. Koch M. and Bubser M. (1994) Deficient sensorimotor gating after 6-hydroxydopamine lesion of the rat medial prefrontal cortex is reversed by haloperidol. Eur. J. Netrosci. 6, 1837-1845.

23. Louilot A., Leoal M. and Simon H. (1989) Opposite influences of dopaminergic pathways to the prefrontal cortex or the septum on the dopaminergic transmission in the nucleus accumbens. An in vivo voltammetric study. Neuroscience $29,45-56$.

24. Lubow R. (1989) Latent Inhibition and Conditioned Attention Theory. Cambridge University Press, New York.

25. McQuade R. D., Duffy R. A., Anderson C. C., Crosby C., Coffin V. L. and Chipkin R. E. (1991) [ ${ }^{3}$ H]SCH39166, a new DI-selective radioligand: in vitro and in vivo binding analyses. J. Neurochem. 57, 2001-2010.

26. Mitchell J. B. and Gratton A. (1992) Partial dopamine depletion of the prefrontal cortex leads to enhanced mesolimbic dopamine release elicited by repcated exposure to naturally reinforcing stimuli. J. Neurosci. 12, 3609-3618.

27. Pakkenberg B. (1987) Post mortem study of chronic schizophrenic brains. Br. J. Psychiat. 151, 744-752.

28. Paxinos G. and Watson C. (1986) The Rat Brain in Stereotaxic Coordinates, 2nd edn. Academic Press, San Diego.

29. Plum F. (1972) Prospects for research on schizophrenia. 3. Neurophysiology, neuropathological findings. Neurosci. Res. Prog. Bull. 10, 384-388.

30. Roberts G. W. and Crow T. J. (1987) The neuropathology of schizophrenia-a progress report. Br. med. Bull. 43, 599-615.

31. Schmidt C. J. and Fadayel G. M. (1995) The selective 5-HT2A receptor antagonist, MDL 100,907, increases dopamine efflux in the prefrontal cortex of the rat. Eur. J. Pharmac. 273, 273-279.

32. Schwarzkopf S. B., Bruno J. P. and Mitra T. (1993) Effects of haloperiol and SCH 23390 on acoustic startle and prepulse inhibition under basal and stimulated conditions. Prog. Neuropsychopharmac. biol. Psychiat. 17, $1023-1036$.

33. Swerdlow N. R., Braff D. L., Geyer M. A. and Koob G. F. (1986) Central dopamine hyperactivity in rats mimics abnormal acoustic startle response in schizophrenics. Biol. Psychiat. 21, 23-33.

34. Swerdlow N. R., Caine S. B. and Geyer M. A. (1992) Regionally selective effects of intracerebral dopamine infusion on sensorimotor gating of the startle reflex in rats. Psychopharmacology 108, 189-195.

35. Tassin J. P. (1992) NE/DA interactions in prefrontal cortex and their possible roles as neuromodulators in schizophrenia. J. neural Transm. 36, Suppl., 135-162.

36. Vezina P., Blanc G., Glowinski J. and Tassin J. P. (1991) Opposed behavioural outputs of increased dopamine transmission in prefrontocortical and subcortical areas; a role for the cortical D-1 dopamine receptor. Eur. J. Neurosci. 3, 1001-1007.

37. Wan F. J. and Swerdlow N. R. (1993) Intra-accumbens infusion of quinpirole impairs sensorimotor gating of acoustic startle in rats. Psychopharmacology 113, 103-109.

38. Weinberger D. R. and Lipska B. K. (1995) Cortical maldevelopment, anti-psychotic drugs, and schizophrenia: a search for common ground. Schizophr. Res. 16, 87-110.

39. Zec R. F. and Weinberger D. R. (1986) The relationship between CT scan findings and neuropsychological performance in chronic schizophrenia. Psychiat. Clin. N. Am. 9, 49-61. 